\title{
A AFETIVIDADE NO DESENVOLVIMENTO DA CRIANÇA. CONTRIBUiÇÕES DE HeNRI WALlON*
}

Ana Rita Silva Almeida**

\section{RESUMO}

O presente trabalho é um estudo teórico com o objetivo de analisar o conceito de afetividade tal como proposto por Henri Wallon. No processo de análise, partiu-se primeiramente da concepção de afetividade, difundida numa perspectiva psicogenética e diferenciada das manifestações de emoção, sentimento e paixão. Retoma-se as questões levantadas durante a análise e sistematiza-se a proposta walloniana da afetividade, destacando as contribuições que fornece ao estudo do desenvolvimento humano, bem como os limites que apontam a necessidade de novos estudos. Por fim, os resultados permitem apontar a importância do estudo da afetividade para a formação do professor. A ausência de uma formação profissional que aborde o estudo da afetividade e suas implicações com a atividade intelectual traz prejuízos para a educação.

Palavras-chave: Afetividade. Desenvolvimento. Criança. Wallon.

\section{INTRODUÇÃO}

No debate sobre a participação da afetividade no desenvolvimento humano, muitas investigações têm se dedicado a discutir a afetividade na sua vinculação com o processo de construção do conhecimento. Defendendo a totalidade do ser humano, alguns trabalhos têm procurado respostas para os problemas educacionais brasileiros, apoiando-se no enfoque walloniano.

O objetivo deste trabalho é analisar o conceito de afetividade, ${ }^{1}$ tal como proposto por Wallon. Focaliza-se a afetividade em sua totalidade, considerando-a em sua relação com a emoção, o sentimento e a paixão.

* Artigo recebido em 29/06/2008 e aprovado em 14/10/2008.

** Doutora em Educação e professora da Universidade Tiradentes-Aracaju-SE. E-mail: analmeida64@hotmail.com 
Iniciar-se-á com o texto em que Wallon apresenta a sistematização sobre afetividade, para, então, completar a análise a partir das teorias do desenvolvimento e das emoções.

Dentre os diversos motivos que justificam um estudo a respeito deste assunto, podemos destacar, inicialmente, o fato de que alguns problemas fundamentais da escola como, por exemplo, relação professor-aluno, dificuldades de aprendizagem, problemas da desatenção são muitas vezes levantados a partir da temática da afetividade. Um outro motivo é a falta de clareza na literatura especializada sobre esse termo, há divergências e questionamentos acerca da sua acepção. Notamos, por exemplo, que a afetividade tem na literatura significado diverso, revelando-se bastante controversa quanto à sua delimitação conceitual em relação à emoção, ao sentimento e à paixão. Esses aspectos - a emoção, o sentimento, a paixão e a afetividade - não têm sido interpretados de maneira comum por diferentes estudiosos, tanto que a terminologia revela-se problemática, sobretudo porque a variedade de sentidos está mesclada entre si, restando suas distinções pouco claras.

Consultando a literatura da psicologia sobre a emoção, percebemos ser esse um problema que perdura até os dias de hoje. Enquanto alguns autores, como, por exemplo, Goleman (1995), identificam emoção com sentimento, outros distinguem-nos, como Damásio (1994). E outros, ainda, não somente os distinguem, mas sobrepõem um ao outro. É o exemplo de Rogers e Kinget, dado por Mahoney (1993), que consideram o termo sentimento como o mais abrangente. Já Wallon, além de distinguir emoção, sentimento, paixão e afetividade, afirma que esta ultima é mais ampla, pois engloba os três primeiros aspectos.

A afetividade é um tema central na obra de Henri Wallon. No entanto, a sua teoria não se encontra sistematizada, isto é, não é apresentada como conjunto de conhecimento organizado, já que as informações encontram-se esparsas em diferentes obras. Duas dessas obras - L'évolution psychologique de l'enfant (1941) e Les origenes du caractère chez l'enfant (1934) - foram esmiuçadas, buscando-se apresentar uma sistematização do posicionamento do autor sobre esse tema.

A posição de Wallon a respeito da importância da afetividade para o desenvolvimento da criança é bem definida. Em sua opinião, ela tem papel imprescindível no processo de desenvolvimento da personalidade e este, por sua vez, se constitui sob a alternância dos domínios funcionais. ${ }^{2}$ 
Como última razão, e talvez a mais importante, encontra-se a dificuldade de compreensão de sua obra, comentada por diversos autores, entre eles Zazzo (1978) e Laterrasse (1981), estendendo-se essa dificuldade ao campo da afetividade. Além do mais, Wallon é um autor que privilegia as relações intrínsecas entre a afetividade e a inteligência, foco pouco abordado nos meios acadêmicos, especialmente no Brasil. Focalizar Wallon, por sua vez, permite estender o debate junto aos que têm se ocupado da tarefa de levar a teoria walloniana aos leitores brasileiros.

Ademais, acreditamos que um enfoque mais claro do conceito terá repercussão na sua aplicação ao processo de formação de professores, introduzindo novos olhares para a relação educativa e, consequentemente, facilitando o processo de ensino e aprendizagem.

\section{MÉTodo}

Por ser uma reflexão sobre a delimitação do conceito de afetividade, o presente trabalho é subsidiado basicamente por aquilo que Wallon formulou em seus escritos. Com respeito aos intérpretes do pensamento do autor, decidiu-se levá-los em conta apenas quando apresentassem informações pertinentes ao esclarecimento dos caminhos a serem seguidos para a análise. É o caso de Tran-Thong (1987), cuja grande contribuição encontra-se na sistematização que fez da teoria de desenvolvimento walloniana e que, por sua vez, nos forneceu maiores informações sobre os textos nos quais, segundo ele, Wallon trata dos estágios.

A construção deste estudo compreendeu dois procedimentos complementares. Um se refere à pesquisa bibliográfica que incluiu a coleta e seleção dos textos e o outro sua leitura e análise, bem como sua organização e redação.

Quanto à pesquisa bibliográfica, esta foi iniciada a partir do levantamento bibliográfico sobre Wallon que René Zazzo apresenta em seu livro, Pychologie et marxisme, de 1975. Além dos textos selecionados nesta listagem, realizou-se um levantamento na Revue Enfance e em bibliotecas internacionais. Para a aquisição desse material, foram utilizados serviços de informática disponíveis, como a Internet, a multimídia, o CD-ROM, bem como visitas a bibliotecas em Paris. Além disso, contamos com o auxílio do Centro Franco-Brasileiro de Documentação Técnico-Científica (Cendotec) para a identificação de algumas obras. 
Obteve-se como produto final desse momento uma listagem de títulos. Iniciou-se pela seleção de um conjunto de textos, a partir da observação do título, da data da publicação da obra, da leitura da introdução e da bibliografia. Os textos selecionados foram os que poderiam permitir o estudo conceitual proposto.

Dada essa primeira definição de textos com os quais se trabalharia, partiu-se então para a leitura do material. Realizou-se uma leitura preliminar, inicialmente buscando identificar os textos ou trechos em que apareciam os temas relacionados ao nosso objetivo.

Tomando-se como referência a sistematização de 1941, que foi cuidadosamente dissecada, levantaram-se questões que passaram a nortear o trabalho realizado com a teoria do desenvolvimento e que, segundo acreditamos, permite dar conta dos aspectos mais importantes do conceito de afetividade, bem como das emoções, dos sentimentos e das paixões.

Na segunda fase de leitura, que inclui os textos referentes à teoria do desenvolvimento e o livro Les origenes du caractère chez l'enfant, iniciou-se o desmembramento efetivo do conceito de afetividade. Vale ressaltar que, aqui, os textos precisaram ser lidos mais de uma vez. As várias leituras ocorreram, entre outros motivos, pela dificuldade de encontrar uma definição sobre o conceito na obra.

A teoria das emoções foi analisada com o objetivo de procurar identificar o que Wallon acrescenta sobre a afetividade, bem como para encontrar respostas às questões levantadas a partir dos textos sobre a teoria do desenvolvimento. No decorrer dessa análise, foram identificados vários textos ilustrativos dos quais foram selecionados aqueles que continham informações novas, completavam conceitos já levantados ou permitiam levantar questões sobre o conceito de afetividade.

$\mathrm{Na}$ apresentação dos diferentes capítulos do trabalho, optou-se por ilustrar com passagens as argumentações do autor. Tais passagens apresentam recortes de trechos pertinentes à discussão ou relacionados diretamente ao assunto específico focalizado.

\section{Resultados}

Conceitualmente, a afetividade deve ser distinguida de suas manifestações, diferenciando-se do sentimento, da paixão, da emoção. ${ }^{3}$ Em outras palavras, afetividade é o termo utilizado para identificar um 
domínio funcional abrangente e, nesse domínio funcional, aparecem diferentes manifestações: desde as primeiras, basicamente orgânicas, até as diferenciadas como as emoções, os sentimentos e as paixões.

O seu desenvolvimento depende da ação de dois fatores: o orgânico e o social. Entre esses dois fatores existe uma relação estreita tanto que as condições medíocres de um podem ser superadas pelas condições mais favoráveis do outro. Essa relação recíproca impede qualquer tipo de determinismo no desenvolvimento humano, tanto que "a constituição biológica da criança ao nascer não será a lei única do seu futuro destino. Os seus efeitos podem ser amplamente transformados pelas circunstâncias sociais da sua existência, onde a escolha individual não está ausente" (Wallon, 1959, p. 288). Ao longo do desenvolvimento do indivíduo, esses fatores em suas interações recíprocas modificam tanto as fontes de onde procedem as manifestações afetivas quanto as suas formas de expressão. A afetividade que inicialmente é determinada basicamente pelo fator orgânico passa a ser fortemente influenciada pela ação do meio social. Tanto que Wallon defende uma evolução progressiva da afetividade, cujas manifestações vão se distanciando da base orgânica, tornando-se cada vez mais relacionadas ao social - e isso é visto tanto em 1941, quando ele fez referência à afetividade moral, quanto em suas teorias do desenvolvimento e das emoções, que permitiram evidenciar o social como origem da afetividade.

Enquanto as primitivas manifestações de tonalidade afetiva são reações generalizadas, mal diferenciadas, as emoções, por sua vez, constituem-se em reações instantâneas e efêmeras que se diferenciam em alegria, tristeza, cólera e medo. Já o sentimento e a paixão são manifestações afetivas em que a representação torna-se reguladora ou estimuladora da atividade psíquica. Ambos são estados subjetivos mais duradouros e têm sua origem nas relações com o outro, mas ambos não se confundem entre si.

A afetividade, com esse sentido abrangente, está sempre relacionada aos estados de bem-estar e mal-estar do indivíduo. Assim, podemos afirmar a existência de manifestações afetivas anteriores ao aparecimento das emoções. As primeiras expressões de sofrimento e de prazer que a criança experimenta com a fome ou a saciedade são, do nosso ponto de vista, manifestações com tonalidades afetivas primitivas. Estas manifestações, ainda em estágio primitivo, têm por fundamento o tônus, o qual mantém uma relação estreita com a afetividade durante o processo 
de desenvolvimento humano, pois o tônus é a base de onde sucedem as reações afetivas.

Quando os motivos que provocam os estados de bem-estar e malestar estão primordialmente ligados às sensibilidades interoceptivas, proprioceptivas e exteroceptivas, temos uma etapa em que a afetividade é de base orgânica - a chamada afetividade orgânica. Quando os motivos que provocam os estados de bem-estar e mal-estar já não são limitados às sensibilidades íntero, próprio e extero, mas já envolvem a chamada sensibilidade ao outro, a afetividade passa para um outro patamar, já que de base fortemente social - a chamada afetividade moral, na terminologia usada por Wallon em 1941. Assim, a afetividade evolui para uma ordem moral e seus motivos são originados das relações indivíduo-outrem, sejam relações pessoais ou sociais.

Ao se defender que a afetividade em seus primórdios é basicamente orgânica, chama-se a atenção para o fato de que, mesmo nos períodos em que o desenvolvimento do ser humano sofre limites de seu aparato fisiológico, o domínio afetivo está iniciando seu desenvolvimento. E o limite fisiológico vai ser superado pelo importante papel desempenhado pelo meio social na evolução da criança.

A importância das relações humanas para o crescimento do homem está escrita na própria história da humanidade. O meio social é uma circunstância necessária para o desenvolvimento do indivíduo. Sem ele, a civilização não existiria, pois foi graças à agregação dos grupos que a humanidade pôde construir os seus valores, os seus papéis, a própria sociedade. Cruzando psicogênese e história, Wallon demonstrou a relação estreita entre as relações humanas e a constituição da pessoa, destacando o meio físico e humano como um par essencial do orgânico na constituição do indivíduo. Sem ele não haveria evolução, pois o aparato orgânico não é capaz de construir a obra completa que é a natureza humana, que pensa, sente e se movimenta no mundo material.

Analisando a teoria do desenvolvimento, podemos identificar, em cada estágio, os tipos de manifestação afetiva que são predominantes, em virtude das necessidades e possibilidades maturacionais. O estágio impulsivo é marcado pelas expressões/reações generalizadas e indiferenciadas de bem-estar e mal-estar; o estágio emocional pela diferenciação das emoções - as reações ou atitudes de medo, cólera, alegria e tristeza; no estágio personalista e no da adolescência e puberdade, por outro lado, 
evidenciam-se reações sentimentais e passionais, sendo o sentimento mais marcante neste último estágio.

Um fato nos chamou a atenção ao analisar as manifestações afetivas que ocorrem nos estágios do desenvolvimento. Pôde-se perceber que, em alguns estágios, predominam uma determinada manifestação afetiva. Quanto ao fato de os sentimentos se evidenciarem mais nos estágios personalista e da puberdade, isso ficou claro pela sua dependência da representação. As paixões não apareceram como predominantes em nenhum estágio, bem como também conseguimos saber pouco sobre essa categoria afetiva. Já as emoções são manifestações suscetíveis de aparecer em qualquer fase, muito embora Wallon não as mencione no decorrer dos estágios personalista e da puberdade.

Há que se destacar que, de todas as manifestações afetivas, a emoção é a mais explorada por Wallon. Em seu livro Les origines $d u$ caractère chez l'enfant, o autor analisa a emoção em sua gênese, apresentando as modificações que sucedem desde o seu aparecimento até o estágio personalista. Para ele, a emoção é uma forma de exteriorização da afetividade que evolui como as demais manifestações, sob o impacto das condições sociais.

É interessante perceber a relação complexa entre a emoção e o meio social, particularmente, o papel da cultura na transformação das suas expressões. Se, por um lado, a sociedade especializa os meios de expressão da emoção, transformando-os em instrumentos de socialização, por outro lado, essa especialização tende a reprimir as expressões emocionais. As formas de expressão tornam-se cada vez mais socializadas, a ponto de não expressarem mais o arrebatamento característico de uma emoção autêntica.

Quanto aos sentimentos e às paixões, Wallon traz menos informações do que as relativas às emoções; no entanto, o autor deixa claro que são posteriores às emoções, só aparecendo mais tarde, quando começam a atuar as representações. O progresso das representações mentais dá sustentação ao surgimento dessas duas manifestações afetivas. A relação de interdependência dos domínios afetivo e cognitivo mais uma vez se evidencia, pois ao desenvolvimento do campo da racionalidade relaciona-se a ampliação do campo afetivo, com outras manifestações de afetividade, além das emoções.

Wallon sem dúvida foi o autor que soube muito bem privilegiar a relação entre os domínios afetivo e cognitivo, na medida em que criou 
uma teoria de desenvolvimento da personalidade. Ocupando-se em estudar a passagem do orgânico ao psíquico, verificou que, nesse processo, ocorre concomitantemente o desenvolvimento de ambos os domínios. $\mathrm{O}$ desenvolvimento da personalidade oscila entre movimentos ora afetivos, ora cognitivos, que são interdependentes; em outras palavras, à medida que a afetividade se desenvolve, interfere na inteligência e vice-versa.

$\mathrm{Na}$ obra walloniana, a afetividade constitui um domínio funcional tão importante quanto o da inteligência. Afetividade e inteligência constituem um par inseparável na evolução psíquica, pois, embora tenham funções bem definidas e diferenciadas entre si, são interdependentes em seu desenvolvimento, permitindo à criança atingir níveis de evolução cada vez mais elevados. É de se notar que entre a emoção e a atividade intelectual existe interdependência, mas também oposição, pois, ao mesmo tempo em que ambas estão presentes na unidade do desenvolvimento, a emoção se esvai diante da atividade intelectual.

Assim, existe entre a emoção e a inteligência uma relação antagônica; sua relação de interdependência não anula a incompatibilidade de seus paroxismos. No entanto, se esse antagonismo é claro, no que se refere à relação inteligência-emoção, não obtivemos muitas informações sobre as relações inteligência-sentimento e inteligência-paixão. Como essas manifestações afetivas são de natureza representacional, diferentemente da emoção; se são de natureza representacional, não apresentam incompatibilidade com a inteligência. Portanto, seria estranho supor que o antagonismo presente na relação emoção-inteligência também ocorra nas relações inteligência-sentimento e inteligência-paixão. Ao contrário, as informações disponíveis nos textos analisados são indicativas de que essas duas últimas manifestações afetivas necessitam do desenvolvimento da inteligência, levando-nos a acreditar que o antagonismo se conserva apenas na relação inteligência-emoção.

Concordamos com Heloysa Dantas (1992) sobre a possibilidade de haver etapas de desenvolvimento da afetividade, pois Wallon parece propor uma evolução da afetividade que, segundo interpretamos, inicia nos primeiros dias de vida e se prolonga no processo de desenvolvimento, diferenciando-se em suas formas de expressão sob a influência social. Acreditamos que essa proposição é plausível, na medida em que os estados de bem-estar e mal-estar apresentam-se primitivamente, já com conotações afetivas, relacionados às sensibilidades orgânicas e posteriormente diferenciam-se em manifestações diversas, como as emoções, os 
sentimentos e as paixões. Essas manifestações vão aparecendo em períodos diferentes da evolução infantil, e vão incorporando as conquistas realizadas no domínio cognitivo, modificando suas formas.

Embora a análise realizada no presente trabalho não apresente informações suficientes para permitir delimitar os estágios de desenvolvimento da afetividade do indivíduo, Wallon sugere sua evolução ao mostrar que a afetividade se desenvolve em um processo que, se inicialmente tem forte componente orgânico (a chamada afetividade orgânica), posteriormente incorpora cada vez mais o fator social (a afetividade moral). De fato, Wallon sugere uma evolução da afetividade. No entanto, sua proposta não permite vislumbrar muito além das formas infantis de afetividade, pois não fornece dados suficientes relativos ao adolescente e ao adulto.

A contribuição de Wallon para a pedagogia científica está na compreensão do indivíduo em sua totalidade. Durante a análise, pudemos verificar que a teoria do desenvolvimento privilegia o desenvolvimento da pessoa, tendo cada estágio uma direção específica e mantendo, em conjunto com as condições de existência, uma relação recíproca. Ao enfatizar a preponderância alternada dos domínios do ato motor, da afetividade, do conhecimento e da pessoa, Wallon abre maiores perspectivas para a compreensão do desenvolvimento humano. Particularmente referindo-nos à relação entre a afetividade e a inteligência, acreditamos que este autor traz uma grande contribuição para a educação. Embora não tendo uma teoria de ensino, suas interpretações acerca dos problemas educacionais e psicológicos, se não dão respostas que possam ser prontamente aplicadas, indicam possíveis caminhos por onde buscá-las. Além, evidentemente, de gerar novas questões e instigar a reflexão teórica.

Segundo Tran-Thong (1969), a pedagogia walloniana defende uma educação que não exclui em nenhuma hipótese as crianças com dificuldades escolares ou com comportamentos inadequados. Para Wallon, as crianças com comportamentos inadequados (desatenção, agitação, indisciplina) não podem conviver num ambiente repressivo e coercitivo; elas precisam de um ambiente favorável às suas características, de modo a poder conviver com a coletividade. Lidar com esses comportamentos inadequados tem como grande saída o domínio da afetividade, pois eles, geralmente, são decorrentes de uma vida afetiva desequilibrada. Para reverter o sentido das reações inadequadas, por exemplo, a fanfarrice na escola, é preciso provocar atos louváveis, mostrando ao indivíduo do 
que ele é capaz. Essa possibilidade de reverter um sentimento negativo, despertando um positivo, está baseada no princípio walloniano de que todo sentimento contém o seu contrário, ou seja, é ambivalente.

Embora em sua proposta seja muito enfatizado o lugar que ocupa a afetividade no desenvolvimento infantil, Wallon não descuida do desenvolvimento da inteligência e da importância do papel da escola nisso. Tanto quanto Wallon em sua proposta, o presente trabalho não se propõe a negligenciar outros aspectos do desenvolvimento em função da primazia da afetividade. Com Malrieu, acreditamos que "não podemos fazer da afetividade um tipo de comportamento separado de todos os outros; ela não pertence a uma zona independente daquela que comanda as atividades sensoriais, motrizes, sociais, intelectuais; reagindo a estas, ela as faz participar pouco ou muito de seu desenvolvimento" (1976, p. 162). Assim, defendemos que o desenvolvimento do sujeito como totalidade não pode ser promovido se direcionarmos nossa prática para uma educação meramente intelectualista. Não esquecemos que o período escolar é um momento de intensa atividade intelectual, mas gostaríamos de lembrar que, se por um lado adquirir conhecimento e evocá-lo, quando necessário, implica memorização, por outro lado a memória depende também de condições afetivas.

As pesquisas wallonianas sobre a afetividade trouxeram contribuições para questões relativas à atenção e ao interesse das crianças nas atividades escolares. De acordo com Tran-Thong (1969), Wallon defende que a escola deve ser oficialmente responsável pela personalidade infantil, devendo se interessar por tudo o que concerne à criança, seja do ponto de vista biopsicológico, seja das condições materiais e sociais de sua existência, para então poder promover um ambiente apropriado ao desabrochar de suas habilidades. Uma criança subalimentada e que habita num ambiente sujo poderá vir a apresentar inércia, instabilidade, agitação, problemas de atenção e fadiga.

Sabemos, em verdade, que a afetividade é influenciada por outros aspectos que independem da vontade da família e da escola. Segundo Malrieu, o equilíbrio afetivo da criança está também à mercê dos homens, ou seja, da rixa e do ódio cultivado na sociedade, além, evidentemente, da contra-educação sexual que "consiste em uma exaltação do instinto sexual, acompanhado, aliás, de pseudotabus; junto a isso existe ainda uma mentalidade céptica e pessimista que concerne ao poder dos homens sobre os acontecimentos sociais, como as guerras" (1976, p. 171). 
Embora tudo isso influencie o desenvolvimento afetivo e cognitivo da criança e embora não possa remediar diretamente as condições sociais inadequadas, não se pode esquecer que a escola é um ambiente que exerce uma grande reviravolta na vida da criança. Por isso, não se deve esquecer as características individuais e as condições de vida da criança, muito menos desconsiderá-las no planejamento de suas atividades. Ignorar as condições de vida tanto quanto as capacidades infantis significa cruzar os braços diante das dificuldades que a criança atravessa ao submeter-se às expectativas e regras do ambiente escolar.

Um outro aspecto que as investigações wallonianas permitem explorar na educação é a relação professor-aluno. Suas investigações psicológicas sobre a evolução da inteligência, das atitudes e do caráter esclareceram certas questões sobre a necessária formação do professor. Segundo Tran-Thong (1969), Wallon considera que o professor precisa ter conhecimento dos problemas sociais de sua época, assumindo uma postura ativa e consciente diante deles. Somente conhecendo os valores morais de seu tempo e as relações sociais vigentes, poderá orientar seus alunos diante da realidade de seu país.

Um último aspecto diz respeito à necessidade de o meio social evitar despertar nas crianças determinados sentimentos negativos, como hostilidade, desprezo, ciúme e inveja que em nada contribuem para o convívio em sociedade. Ou seja, se desejamos criar na nossa sociedade cidadãos comprometidos com os outros, devemos incentivar nas crianças, desde cedo, a coletividade, despertando a cooperação e não a rivalidade. A família e a escola têm uma participação íntima, pois são um meio favorável à aprendizagem de sentimentos que marcam a vida da criança. Por isso, já nos primeiros anos escolares, o professor deve ser competente em preparar a criança para viver em coletividade, incentivando o trabalho em grupo. Em outras palavras, já no jardim de infância, o professor deve procurar desenvolver sentimentos nobres que permitem ao indivíduo atuar como cidadão na sociedade.

A relação mantida em sala de aula com os alunos também deve ser cultivada com sentimentos positivos. Durante o ensino da matéria, o professor deve procurar evitar desgosto ou opressão e criar um clima de igualdade de expressão e oportunidades entre todos, evitando, assim, um tratamento desigual entre os alunos. 
As matérias ensinadas podem provocar uma desadaptação geral ou particular que depende frequentemente de uma inaptidão intelectual inicial, mas que pode se duplicar em uma atitude de inibição e hostilidade diante do professor. O professor pode ser também causa direta de perturbações. A hostilidade, de certo modo, pode resultar do insucesso da criança, da severidade do mestre, dos motivos pessoais originados no meio familiar ou nos motivos afetivos que dependem da história íntima da criança. (Tran-Thong, 1969, p. 95)

Ressalta Tran-Thong que alguns distúrbios ou algumas reações inadequadas na criança têm origem na severidade ou rudez do professor. Essas atitudes, muitas vezes, são os motivos da inibição e recalque da criança em sala de aula. Por isso, o professor deve procurar ajudar a criança a resolver seus complexos, suscitando nela um interesse novo e uma conduta diferente da antiga. Ao contrário das sanções que despertam a ansiedade, deve-se recorrer às atividades que têm uma ação libertadora sobre as reações inadequadas - este é o caso do desenho e da narrativa.

Se a escola tem papel fundamental na formação da personalidade infantil, muito antes da escola, a família tem sua parcela de contribuição. A família tem uma participação essencial sobre o aspecto afetivo, tanto que os problemas familiares, quando não bem administrados diante dos filhos, podem ter efeitos nocivos para o equilíbrio afetivo da criança. Muitas vezes, a impaciência da mãe leva-a a reprimir o nervosismo da criança com punições corporais. Essa atitude nada resolve, podendo desencadear outras reações mais difíceis na criança. Além disso, os pais devem estar cientes de que o desenvolvimento da afetividade inicia muito cedo, já nas primeiras manifestações que são anteriores ao aparecimento das primeiras emoções. Em outras palavras, a relação que se estabelece, já nos primeiros contatos com a criança durante os cuidados alimentares, constitui a base da afetividade da criança. Como salientado, o desenvolvimento da afetividade inicia nos primeiros dias de vida na relação mãe-recém-nascido, prolongando-se por toda a vida.

\section{Conclusão}

Parece-nos que a afetividade é, ainda, um campo aberto para investigações. Wallon indica caminhos a serem trilhados para estudos complementares ao estabelecer nítida diferença, em sua obra, entre a afetividade e suas manifestações e ao identificar que, no desenvolvimento 
humano, existem estágios que são predominantemente afetivos. Cremos que, se pudéssemos separar os estágios predominantemente afetivos dos demais, apenas para efeito de análise, já teríamos, possivelmente, um caminho, mesmo que incipiente, a ser trilhado. Por conseguinte, acreditamos que uma aproximação cada vez maior com a proposta walloniana da afetividade permitirá uma compreensão dos possíveis desdobramentos e limites nela existentes.

Finalizando, consideramos que seria ingenuidade supor que uma teoria contém uma explicação pronta, já que os autores nem sempre têm tempo ou condições para desvendar tudo. Seria do mesmo jeito ingenuidade achar que aqueles que se servem de uma teoria podem também responder a todas as questões que surgem durante o trabalho. Como consideramos verdadeiras essas duas afirmações, deixamos explícito que este trabalho é uma tentativa de sistematizar a proposta walloniana da afetividade, tentativa essa que deverá ser seguida por novos estudos visando continuar o trabalho iniciado por Wallon e, principalmente, ampliar os horizontes das pesquisas wallonianas no Brasil.

Embora a análise realizada no presente trabalho não apresente informações suficientes para permitir delimitar os estágios de desenvolvimento da afetividade do indivíduo, Wallon sugere sua evolução ao mostrar que a afetividade se desenvolve em um processo que, se inicialmente tem forte componente orgânico (a chamada afetividade orgânica), posteriormente incorpora cada vez mais o fator social (a afetividade moral). De fato, Wallon sugere uma evolução da afetividade. No entanto, sua proposta não permite vislumbrar muito além das formas infantis de afetividade, pois não fornece dados suficientes relativos ao adolescente e ao adulto.

Parece-nos que a afetividade é, ainda, um campo aberto para investigações. Wallon indica caminhos a serem trilhados para estudos complementares ao estabelecer nítida diferença, em sua obra, entre a afetividade e suas manifestações e ao identificar que, no desenvolvimento humano, existem estágios que são predominantemente afetivos. Cremos que, se pudéssemos separar os estágios predominantemente afetivos dos demais, apenas para efeito de análise, já teríamos, possivelmente, um caminho, mesmo que incipiente, a ser trilhado. Por conseguinte, acreditamos que uma aproximação cada vez maior com a proposta walloniana da afetividade permitirá uma compreensão dos possíveis desdobramentos e dos limites nela existentes. 


\begin{abstract}
This paper uses a theoretical approach to study the concept of affectivity as proposed by Henri Wallon. The analysis begins with the concept of affectivity in a psychogenetic and differentiated perspective of the manifestations of emotion, feeling and passion. The Wallonian theory of affectivity is systematized, emphasizing its contributions to the study of human development as well as the limits that indicate the need for new studies. Finally, the results allow us to consider the importance of the study of affectivity for the formation of teachers. The lack of a professional training that considers affectivity and its implications for intellectual activity is damaging to education. The consequences of this omission are reflected in the classroom and in interactions where pedagogical practice is established.
\end{abstract}

Keywords: Development. Affectivity. Child. Wallon.

\title{
NOTAS
}

1. Wallon faz referência a quatro domínios funcionais: $\mathrm{o}$ ato motor; o conhecimento; a afetividade e a pessoa. São eles que dão uma determinada direção ao desenvolvimento e, no decurso da vida humana, cada um desses domínios tem seu próprio campo de ação e organização, mas mantém em relação com os demais uma espécie de mecanismo interfuncional.

2. Para maior aprofundamento do assunto, consultar: Almeida, Ana Rita S. $A$ emoção na sala de aula. 6. ed. Campinas: Papirus, 2007.

3. São reações que têm por base os estímulos recebidos pelos receptores do organismo. Estes são de três tipos: interoceptores, cujas excitações provêm de estímulos internos e é o ponto de partida de reflexos vegetativos. Proprioceptores são habitualmente estimulados pelas atividades próprias dos órgãos que os contém, por exemplo, os receptores dos músculos. Exteroceptores que são habitualmente estimulados por agentes externos ao organismo.

\section{REFERÊNCIAS}

ALMEIDA, A. R. S. A concepção walloniana de afetividade. Uma análise a partir das teorias das emoções e do desenvolvimento. 1999, 167 fl. São Paulo: Tese (Doutorado em Educação: Psicologia da Educação) - Programa de PósGraduação em Educação: Psicologia da educação, Pontifícia Universidade Católica de São Paulo, São Paulo, 1999.

DAMÁSIO, A. R. O erro de Descartes; emoção, razão e o cérebro humano. Tradução de Dora Vicente e Geórgia Segurado. São Paulo: Companhia das Letras, 1996. 
DANTAS, H. A afetividade e a construção do sujeito na psicogenética de Wallon. In: LA TAILLE, Y. de et al. Piaget, Vygotski, Wallon. Teorias psicogenéticas em discussão. São Paulo: Summus, 1992.

GOLEMAN, D. Inteligência emocional; a teoria revolucionária que define o que é ser inteligente. Tradução de Marcos Santana. Rio de Janeiro: Objetiva, 1995.

LATERRASSE, C. Les origines de l'affectivité chez l'enfant dans la théorie wallonienne. In: MALRIEU, P. et al. Henri Wallon: pour le centenaire de sa naissance. Toulouse: Service des Publications de l'Université de Toulouse-Le Mirail, Série A- Tome XIV, 1981. p. 64-81.

MAHONEY, A. A. Emoção e ação pedagógica na infância: contribuições da psicologia humanista. Temas em Psicologia. São Paulo: Sociedade Brasileira de Psicologia, (3): 67-72,1993.

MALRIEU, P. La vie affective de l' enfant. Paris: Editions du Sacarabée, 1976.

TRAN-THONG. Estádios e conceito de estádios de desenvolvimento da criança na psicologia contemporânea. Tradução de Manuel Maia. Lisboa: Afrontamento, 1987, v. I, cap. I, II. p. 159-325.

. La pensée pédagogique d' Henri Wallon.Trad. Manuel Maia. Paris: Presses Universitaires de France, 1969.

WALLON, H. Les origines du caractère chez l'enfant. Les préludes du sentiment de personalité. Paris: Presses Universitaire de France, 1993. 1994.

. L'évolution psychologique de l'enfant. 9. ed. Paris: Armand Colin,

. Les milieux, les groupes et la psychogenèse de l'enfant. Enfance, Paris, (3-4): 287-296, mai-oct., 1959.

ZAZZO, R. Henri Wallon: psicologia e marxismo. Tradução de Calado Trindade. Lisboa: Vega, 1978. 